\title{
Türkiye Tohumculuk Sektöründeki Gelişmeler ile Bu Gelişmelerin Sertifikalı Tohumluk Kullanımına ve Verim Üzerine Muhtemel Etkileri
}

\author{
*Seydi Ahmet BAĞCl ${ }^{1}$ Kamil YILMAZ² \\ ${ }^{1}$ Selçuk Üniversitesi, Sarayönü Meslek Yüksekokulu, Konya \\ ${ }^{2}$ TAREKS A.Ş., Ankara \\ *Sorumlu yazar e-posta (Corresponding author; e-mail): abagci@selcuk.edu.tr
}

\begin{abstract}
Öz
İnsan ve hayvan beslenmesi için tarımda verim ve üretimin artırılmasında, en önemli teknolojik girdi tohumdur. Bitkisel üretimde üstün nitelikli tohum kullanılması kendine döllenen türlerde \%20-30'luk, yabancı döllenen türlerde kullanılan hibrit tohumluklarla ise \%100'ün üzerinde bir verim artışı sağlanabilmektedir. Verimlilik ve üretimde son derece önemli olan tohumun bu özelliğinin tarımda kullanılabilmesi ise tohumculuk sektörünün gelişmesi, kamu ve özellikle de özel sektör için gerekli olan yapısal ve yasal düzenlemelere ve yatırımlara bağııdır. Ülkemizde 1980'li yıllara kadar kamu ağırıklı, 1985'li yıllardan itibaren özel sektörün de yer aldığı, bilimsel ve teknolojik gelişmeler, tohum sistemlerindeki değişimler esas alınarak dünya ile bütünleşmeyi hedefleyen tohumculuk politikaları benimsenmiştir. Bu çerçevede 2004 yılında "Yeni Bitki Çeşitlerine Ait Islahçı Haklarının Korunması" ve 2006 yılında "Tohumculuk" kanunlarının kabulü ile Türk tohumculuk sektörü önemli ivmeler kazanmış ve yeniden yapılanmaya başlamıştır. Tohumculuk sektöründeki gelişmelere bağlı olarak ülkemizde sertifikalı tohumluk üretim ve kullanımı yıllar içinde artmıştır. Sertifikalı buğday tohumluk üretimi 1996 yılında 110 bin ton iken 2013 yılında 421 bin tona ulaşmıştır. Özel sektör tohumculuğundaki gelişme daha hızlı olmuş ve 1996 yılında sertifikalı tohumluk buğday üretimindeki payı \%4 den 2013 yılında \%58'e yükselmiştir. Sertifikalı tohumluk kullanım desteğinden 2005 yılında 5.4 milyon da alan yararlanırken 2013 yılında ise 15.5 milyon da alan sertifikalı tohumluk kullanım desteğinden faydalanmıştır. Türkiye ortalama buğday verimi yıllar içinde artış göstermiş; 1996 yılında dekara verim 198 kg, 2006 yılında 236 kg ve 2013 yılında 284 kg yükselmiştir. Verimde meydana gelen bu artışta sertifikalı tohumluk kullanımının etkisi göz ardı edilemez.
\end{abstract}

Anahtar Kelimeler: Tohumculuk, tohum, sertifikalı tohum, verim

\section{Developments of Seed Sector in Turkey and its Possible Effect on Certified Seed Use and Crop Yield}

\begin{abstract}
Seed is the most important input in agriculture for increasing yield and production for human nutrition and animal feeding. Seed quality with appropriate agronomic practices may increase yield of crops up to 20 $30 \%$ in self-pollinated crops whereas $100 \%$ in hybrids. To get benefit from the advantage of certified seed depends on the level of development of seed sectors in the countries. However, development of seed sectors requires structural adjustment, legal arrangements and investments for seed sectors in public and especially private sectors. In our country seed sector was mainly controlled by the public until 1980. Since the 1985s, seed sector including private sector aiming to been integrated with the world seed policies based on to scientific and technological developments and changes in seed systems has been developed. In this context, Turkish seed sector have gained momentum and began restructuring with the adoption of the laws, "Protection of Breeder's Rights for New Plant Varieties" in 2004 and "Seed" in 2006. Depending on the developments of certified seed sector in our country, seed production and use has increased over the years. While it was 110 thousand tons in 1996, certified wheat seed production reached to 421 thousand tons in 2013. Private seed sector has been developed faster and their share in certified wheat seed increased to 58\%in 2013 from 4\% in 1996. Whereas approximately 5.4 million decare area was subsided for certified seed usage in 2005, it reached to 15.5 million decare in 2013. Turkey showed an increase in the average yield of wheat in the year; In 1996, the yield per decare to 198 kg, 236 kg in 2006 and reached 284 kg in 2013. The impact of certified seed use in this increase occurred in the yield cannot be underestimated.
\end{abstract}

Keywords: Seed, certified seed, subsidy, wheat, yield 


\section{Giriş}

ön nsanların beslenmesi ve bitkisel üretimde en önemli tarımsal girdilerden biri tohumdur. Tohum, güvenli ve kaliteli gıdanın da önemli halkalarından biridir. Tarımda kullanılan ilk tarımsal girdi olmakla birlikte bir ekonomik faaliyet olarak tohumun bir endüstri haline gelişi son 150 yıla ait bir gelişmedir. Geçen yüzyıl tarımda önemli ve köklü değişimlerin yaşandığı bir dönem olmuştur. Tarımın ekonomik bir faaliyete ve endüstriye dönüşmesine paralel olarak onun ihtiyaç duyduğu en temel girdi olan tohumluk endüstrisi de benzer bir gelişme göstermiştir. Diğer yandan, son 50-60 yılda önemli ilerlemeler kaydeden genetik bilimi, bitki ıslahı ve özellikle 1990'larda ivme kazanan bitkisel biyoteknoloji, tohumluk endüstrisinin giderek bilime dayalı ve ekonomik yönü ağır basan bir sektör haline dönüşmesine katkıda bulunmuştur. Ayrıca sınai ve fikri mülkiyet hakları alanındaki gelişmeler ve 1970'lerden sonra tüm dünyada girerek ağırlığını hissettirmeye başlayan "Bitki Islahçı Hakları" tohumculuk sektörünün güçlenmesine önemli katkılar sağlamıştır.

\section{Ülkemizdeki Tohumculuk Sektöründeki Gelişmeler}

Dünyada ticaretin artması, bitkisel ürünlerin ticareti ve buna bağlı bitkisel üretimin temeli olan tohumluk ticaretinin gelişmesini beraberinde getirmiştir. Ticaretin gelişmesi ise tohumlukların kalite kriterlerinin belirlenmesini gerekli kılmıştır. Tohumlukların kalitesinin laboratuvar ortamında belirlenmesi amacıyla Dünyada ilk laboratuvar 1869 yılında Almanya'da kurulmuş, bunu 1871 yılında Danimarka ve 1876 'da ise ABD'de kurulan laboratuarlar izlemiştir. Dünyada tohum sertifikasyonu ile ilgili organizasyonlar ise 1900'lü yılların başlarında kurulmaya başlamıştır. 1906 yılında Almanya'da oluşturulan Avrupa Tohumluk Kontrol Birliği (ESTA)ni, 1908 yılında kurulan Amerika ve Kanada Resmi Tohumluk Sertifikasyon Ajansları Birliği (AOSCA) izlemiştir. 1924 yılında tohumluklardan numune alınması ve laboratuvar analizlerinde belli kuralların ortaya konulması amacıyla Uluslararası Tohum Test Birliği (ISTA) kurulmuştur. Yine aynı yıl uluslararası tohum federasyonu (ISF=FIS) faaliyetine başlamıştır. 1958 yılında özellikle Birleşmiş milletlere üye ülkelerin katılımı ile dünya tohumluk ticaretini kolaylaştırmak ve ülkeler arasındaki uygulama farklılıklarını ve ticaret engellerini en aza indirmek amacıyla OECD tohum sertifikasyon sistemi oluşturulmuştur.
Ulkemiz tarımında planlı ve sistemli tohumculuk faaliyetleri cumhuriyetle birlikte 1925-1930'lu yıllarda araştırma enstitüleri/tohum ıslah istasyonlarının kurulmasıyla başlamıştır. Ancak 1960'lı yıllara kadar bu alanda sağlanan gelişmeler bazı türlerde çeşit geliştirme çabaları ve sınırlı miktarda tohumluk üretiminden öteye gidememiştir. 1963 yılında "Tohumlukların Tescil, Kontrol ve Sertifikasyonu Hakkındaki 308 Sayılı Kanun"un yürürlüğe girmesi ile ülkemiz tohumculuğunda yeni bir dönem açılmıştır. Bu kanunla birlikte çeşit tescili, tohumlukların sertifikasyonu ile kalite kontrolü ve piyasa denetimi konularında Tarım Bakanlığı ilk kez görevler üstlenmiş, tohumluk üretimi konusunda ise daha etkin rol almıştır.

1980'li yıllara kadar Türkiye'de uygulanan kamu ağırlıklı tohumluk politikaları ülke intiyacının yurt içi üretimlerle karşılanması yönünde olmuştur. 1983 yılında tohumluk fiyatlarının.1984'te ise tohumluk ithalatının serbest bırakılması ve serbest piyasa ekonomisinin etkin hale gelmesi ile özel sektör tohumculuğu gelişme fırsatı bulmuştur. Özel sektör girişimciliği zaman içinde tohumluk üretimi, teknoloji transferi, çeşit geliştirme, tohum işleme ve pazarlama konularını da içine alacak şekilde organize olmuştur. Bugün Tohumculuk sektöründeki gelişmelere baktığımızda, üretim, ticaret ve bitki ıslahındaki ilerlemelere paralel olarak uluslararası kural ve normlara, standartlara uygun tohum sistemleri ve teknik ve hukuki mevzuatların bir ülkede oluşturulması intiyacı ortaya çıkmıştır. Bu kapsamda, AB mevzuatlarına teknik olarak uyumlu, Bitki Islahçı Hakları ve Tohum sistemleriyle ilgili düzenlemelere gereksinim duyulmuştur.

Bu amaçla, 15/01/2004 tarihinde yeni Bitki Çeşitlerine Ait Islahçı Haklarının Korunmasına ilişkin kanun, 08/11/2006 tarihinde Tohumculuk Yasası yürürlüğe girmiştir. 2008 ve takip eden yıllarda ise Bitki Çeşitlerinin kayıt altına alınması, tohum-fide kalitesi ve standartları kapsayan ikincil mevzuatlar (Yönetmelik, tebliğ, yönerge, genelge) uygulamaya konulmuştur. Türkiye.1963'te ISTA (Uluslararası Tohum Test Birliği)'ya.1968 yılında OECD Tohum Sertifikasyon Sistemine dahil olmuştur.2007 yılında ise Bitki Islahçı Haklarının Korunması kapsamında UPOV(Uluslararası Yeni Bitki Çeşitlerini Koruma Birliği)'a üye olmuştur. Türkiye, tohumculuk sektörünün yapılanması ile birlikte çeşit tescili, sınai ve fikri mülkiyet hakları kapsamında yeni bitki çeşitlerinin korunması, 
tohum, fide ve fidan sertifikasyonu, tohum üretimi, yurt içi ve uluslararası tohum ticareti ve piyasa denetimi konularda $A B$ ile uyumlu ve uluslararası standartlara uygun mevzuat ve teknik altyapılarını oluşturmuştur. Bunların sonucunda dünya tohum politikalarını oluşturan ve yönlendiren ISTA, OECD ve ISF(Uluslararası Tohum Federasyonu) gibi organizasyonlarda ülkemiz tohum endüstrisi kamu ve özel sektör olarak etkin olmaya başlamıştır

2008 yılından itibaren 5553 Sayılı Tohumculuk Yasası kapsamında özel sektörün yeniden örgütlenmesi ve yapılandırılması önemli ölçüde tamamlanmıştır. Bu bağlamda, Türkiye Tohumcular Birliği ve Alt Birlikler kurulmuştur. Bu birlikler, Bitki Islahçıları Alt Birliği (BISAB), Tohum Sanayicileri ve Üreticileri Alt Birliği (TSÜAB), Fidan Üreticileri Alt Birliği (FÜAB), Fide Üreticileri Alt Birliği (FIDEBİR), Tohum Dağıtıcıları Alt Birliği (TODAB), Tohum Yetiştiricileri Alt Birliği (TYAB), Süs Bitkileri Üreticileri Alt Birliği (SÜSBİR)'dir. Bu birlikler halihazırda sektörün her alanda tamamına yakınını temsil etmektedirler.

Ülkemizde tohum endüstrisinin sektörel yapısını incelediğimizde; Tarla bitkileri ve sebze tohum üretiminde ve ıslahında faaliyet gösteren kuruluşları dört ana gurupta toplayabiliriz. Bunlar, 1-Kamu Tarımsal Araştırma Enstitüleri ve Üniversiteler, 2- TİGEM, 3-Birlikler ve Kooperatifler, 4-Özel sektör tohum şirketleridir. Türkiye'de bu yıl itibariyle, 26 kamu kuruluşu, çok sayıda Birlik ve kooperatifler ile birlikte sayısı 680'i bulan çeşitli boyuttaki yerli ve yabancı sermayeli özel tohumculuk firması tohumculuk alanında faaliyet göstermektedir. 1984-1985'li yıllarda ve sonrasında uygulanan tohumculuk politikaları, sektörde faaliyet gösteren özel kuruluşların sayıca hızla artmasına imkan tanımıştır. Önceleri kamu ağırlıklı bir yapılanma gösteren tohumculuk üretim ve dağıtım sistemi sonraları yerini, bilhassa tarla ve sebze bitkileri türleri tohumculuğunda, özel sektör faaliyetlerinin öne çıktığı bir yapıya bırakmıştır.

Dünya'da tohum endüstrisinin geliştiği kalkınmış ülkeleri esas aldığımızda, bu ülkelerin en az 150-200 yıllık bir sektörel birikime sahip olduklarını, ülkemizde ise özel sektörün yaklaşık 30-40 yıllık, kamunun ise $80-90$ yıllık geçmiş ve deneyime sahip olduğu bir gerçektir. Bütün bu gelişmelerin sonucu olarak 1990 yılında 116 bin ton, 2002 yılında 145 bin ton olan toplam sertifikalı tohumluk üretim ve dağıtımı, 2014 yılında yaklaşık 775 bin tonlara ulaşmıştır. Bu rakamlar bile bazı bitki türlerinde ve toplamda ihtiyacı karşılamadığını ortaya koymaktadır. Ancak son yıllarda elde edilen gelişmeler çok değerlidir.

İhracat ve ithalatla ilgili verilere bakıldığında son yıllarda hem ithalatın, hem de ihracatın önemli oranda arttığını görmekteyiz. 2014 yılı itibariyle ithalat 211.4 milyon ABD doları, ihracat ise yaklaşık 170.2 milyon ABD dolarıdır. 19801990'lı yıllarda sadece ithalat yapan sektör, gelinen noktada ihracatta önemli gelişmeler kaydetmiştir. İhracatta tarla bitkileri (mısır, ayçiçeği, pamuk, buğday, şeker pancarı vb.) tohumluklarının yanında, tamamen Türkiye'de ıslah edilmiş ve geliştirilmiş bazı sebze (domates, biber, hıyar vb.) çeşitlerine ait tohumluklarda önemli yer tutmaktadır.

\section{Tohumculukta Gelişmelerin Verime Muhtemel Etkileri}

Türkiye'nin tohum endüstrisinin genel durumuna baktığımız zaman, ülke olarak tohumculuk sektörünün, çiftçinin, sanayicinin, tüketicinin taleplerini karşılayacak tohum üretim potansiyeli, tohum işleme kapasitesi ve pazarlama imkânına sahiptir. Tohumculuk sektöründe verimli, kaliteli ve abiyotik ve biyotik şartlara uyumlu yeni çeşitlerin katkısı önemlidir. Ülkemizde yurt içinde ve yurt dışında geliştirilen çeşitlerin kayıt altına alınması çalışmaları 1963 yılında 308 Sayılı yasa ve ilgili yönetmelikler ile başlamıştır. 1980 yılında tescilli çeşit sayısı toplam 274 iken, 2015 yılı şubat ayı itibariyle tarla bitkilerinde 53 bitki türünde 2806 tescilli (2049'u üretimde), Sebze türlerinde ise 38 bitki türünde 4249 çeşit (2603'ü üretimde) kayıt altına alınarak ülke tarımının hizmetine sunulmuştur.

Tohumculuk Kanuna bağlı olarak yapılan yeni düzenlemelerle beraber sektörde oluşturulan yapılanma ile sektörün kendi kendini yönetmesi ve getirilen yeni desteklemeler ile sertifikalı tohumluk üretimi ve kullanımı teşvik edilmesi sağlanmıştır. Tohumculuk sektöründeki bu gelişmelere bağlı olarak sertifikalı tohumluk üretim ve kullanımı yıllar içerisinde artış göstermektedir. Sertifikalı buğday tohumluk üretimi 1999 yılında 140 bin ton iken 2014 yılında 403 bin tona ulaşmıştır. Özel sektör tohumculuğu da bu paralel de gelişme göstermiş ve 1999 yılında sertifikalı buğday üretimindeki payı \%8 den 2014 yılında \%64'e yükselmiştir (Şekil 1). Sertifikalı tohumluk kullanım desteğinden 2005 yılında 5.4 milyon da alan yararlanırken 2013 yılında ise 16.0 milyon da alan sertifikalı tohumluk kullanım desteğinden faydalanmıştır. Sertifikalı tohumluk kullanımına destek kapsamında 2005 yılında 67826 çiftçiye 16.5 milyon TL destek 
ödemesi yapılmışken 2013 yılında ise 160625 çiftçiye 124.2 milyon TL ödeme yapılmıştır. Sertifikalı tohumluk kullanım desteği 2005-2013 yılları arasında en fazla 16.3 milyon da alanla ve 89.7 milyon TL ile Konya ilinde kullanılmıştır. Konya ilini 9.8 milyon da ve 57.2 milyon TL ile Diyarbakır, 7.8 milyon da ve 40.7 milyon TL ile Ankara ve 3.5 milyon da ve 20.1 milyon TL ile Şanlıurfa illeri takip etmiştir (1). Sertifikalı tohum kullanımına yapılan desteklemeler ile sertifikalı tohumluk kullanımını arttırmıştır. 2013 yılında Diyarbakır \%47.8 ile en yüksek sertifikalı tohumluk kullanan il olmuştur. Sertifikalı tohumluk kullanım oranında Diyarbakır'ı \%32.4 ile Edirne, \%32.0 ile Mardin ve \%30.3 ile Konya takip etmiştir. İncelenen iller arasında en düşük sertifikalı tohumluk kullanım oranı 0.9 ile Erzurum ve \%0.4 ile Iğdır'da elde edilmiştir (Şekil 2) (2). Sertifikalı tohumluk kullanımı oranı yüksek olan illerdeki (Diyarbakır, Edirne, Konya, Mardin) buğday verimi sertifikalı tohumluk kullanım oranı düşük olan illerdeki (Erzurum, Iğdır, Manisa, Kütahya) buğday verimlerine göre daha yüksek olmuştur (Anonim 2015).

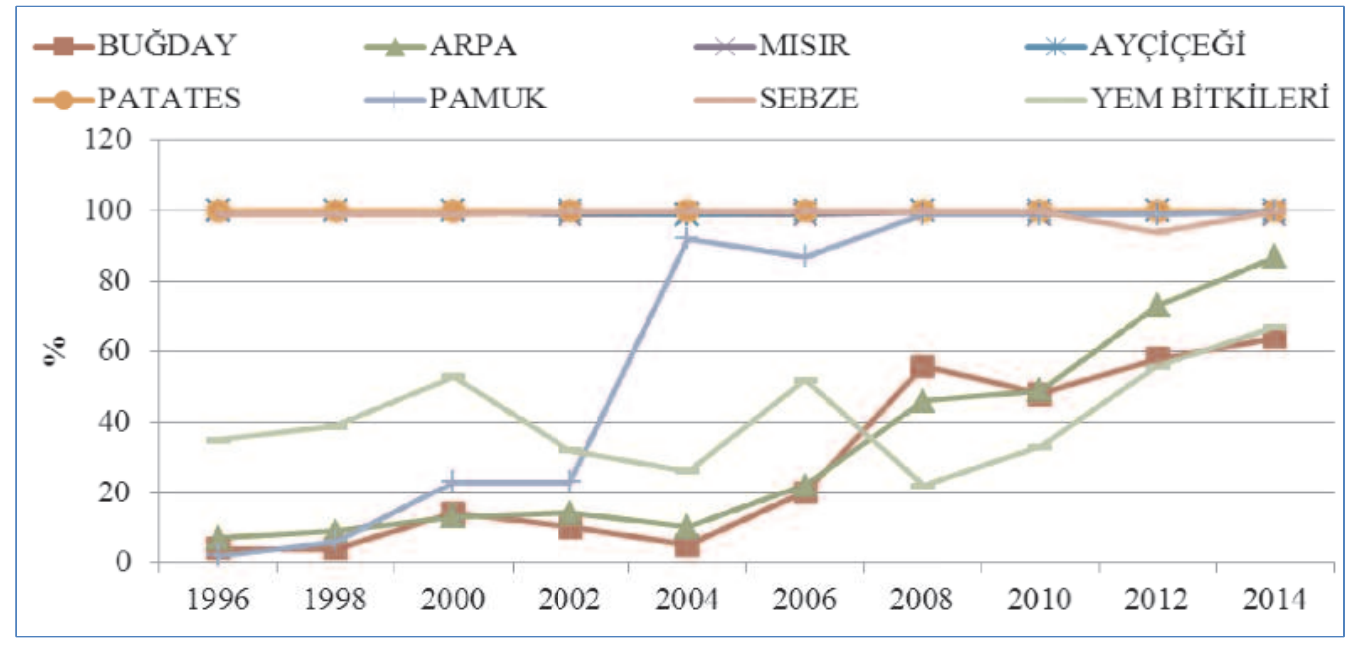

Şekil 1.Tohumluk üretiminde özel sektör payı (http://www.tarim.gov.tr/BUGEM)

Figure 1. Private sectors percentage on seed production (http://www.tarim.gov.tr/BUGEM)

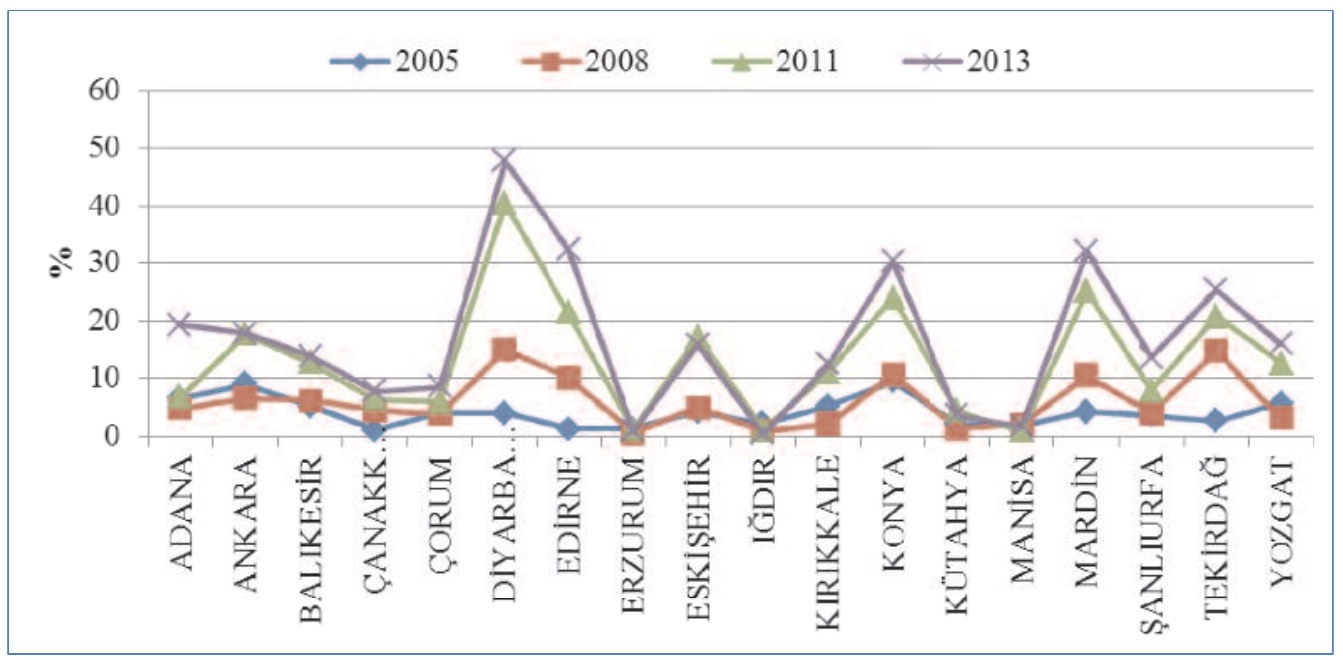

Şekil 1.Bazı illere ait sertifikalı tohumluk kullanım oranları (Sertifikalı tohumluk kullanım oranları BÜGEM kaynaklarına göre yıllar itibari ile sertifikalı tohumluk kullanım desteklemelerinden tahmini olarak hesaplanmıştır)

Figure 1. Sertificated seed usage percentage for some provinces (Data shown here is estimated on sertificated seedling supports by years from BUGEM sources) 
Son on yıl içinde sertifikalı tohum kullanım oranı yüksek olan illerdeki buğday veriminde meydana gelen verim artışında $\left(R^{2}=0.8158\right)$ sertifikalı tohum kullanımının da etkisi göz ardı edilemez.

\section{Sonuç}

Tohumculuk sektörü, Orta Asya ve Ortadoğu ülkeleri, Kuzey Afrika, Balkanlar, Doğu Avrupa gibi bölge ülkelerinde dış satım / pazarlama için önemli bir potansiyele sahiptir. Türkiye, bazı tarla bitkileri türlerinde, Sebze ve bahçe bitkileri açısından önemli bir üretici ülke olması, tarımsal sanayi ve seracılığın gelişmesi nedeniyle hem bazı tarla bitkilerinde, hem de sebze tohumculuğunda önemli fırsat alanlarına sahiptir. Bu alanlarda Pazar analizlerinin iyi yapılması, tohum master planlarının hazırlanması, özellikle ECOSA (Ekonomik İşbirliği ülkeleri Tohum Birliği) ülkelerinde tohum mevzuatının uyumlaştırıması, çeşit tescil ve tohum sertifikasyon sistemlerinin geliştirilmesi ve teknik işbirliği yapılması geleceğe yönelik önemli hususlardan biridir. Tohum endüstrilerinde bitki ıslahı, üretim, teknoloji kullanımı kadar pazarlamada önem verilmesi gereken unsurlardan biridir.

Ülkemizdeki tohumculuğun gelişimi için;

$>$ Sertifikalı tohumluk kullanımı daha da yaygınlaştırılmalı ve sertifikalı tohumluk için yeni destekleme yöntemleri geliştirilerek mevcut sertifikalı tohumluk kullanımı arttırımalıdır. Bunun için sertifikasız tohumdan üretilen mahsul ile sertifikalı tohumdan üretilen mahsule verilen pirim desteği farklı olmalıdır.

$>$ Çok genç olan milli özel tohumluk sektörünün rekabetçi gücü arttırılmalıdır. Sertifikalı tohumluk kullanım desteği ülkemizde ıslah edilen yerli çeşitlere daha yüksek verilmelidir.

$>$ Tohumculuk sektörünün daha sağlıklı gelişmesi için denetime daha fazla önem verilmelidir. Denetim konusunda yapılacak yetki devri ile sektörün kendi kendini denetlemesi sağlanmalıdır.

$>$ Gelişmiş ülkelerde tarıma dayalı milli gelirin \%2.6'sı, Türkiye'de ise \% 0.48'i tarımsal AR-GE çalışmalarına ayrılmaktadır. Bu oran artııılarak özel ve kamudaki araştırmacılara yapılan proje destekleri bu kapsamda daha da geliştirilmeli ve bitki ıslahçılarının eğitimi ile tohumculuk konusundaki eğitimlere önem verilmelidir.
> Ülkenin ihtiyacı olan ürünlerde çeşit ıslah çalışmalarına ağırlık verilmelidir. Başta mısır, ayçiçeği, soya, patates, şeker pancarı ve sebze olmak üzere ülkemizin yerli çeşit geliştirme kapasitesi arttırılmalıdır

Sonuç olarak ülkemiz tohumculuk sektörünün gelecekteki gücünü, yetişmiş ve tecrübeli insan kaynakları, teknik alt yapı, üretim potansiyeli, pazarlama yeteneği, AR-GE çalışmaları ve bitki ve tohum alanındaki bilimsel çalışmalar ile sektöre yapılan destekleme politikaları belirleyici olacaktır.

\section{Teşekkür}

(1) Sayısal veriler Bitkisel Üretim Genel Müdürlüğü Tohumculuk Dairesine ait kayıtlardan düzenlenmiştir. İlgilere katkılarından dolayı teşekkür ederiz.

(2) Sayısal veriler Bitkisel Üretim Genel Müdürlüğü Tohumculuk Dairesine ait kayıtlardan elde edilen rakamlar üzerinden tahmini olarak hesaplanmıştır.

\section{Kaynaklar}

Anonim, 2015. TÜiK, Türkiye İstatistik Kurumu, http://tuikapp.tuik.gov.tr/bitkiselapp/bitkisel.zul (Erişim tarihi: 12.08.2015) 